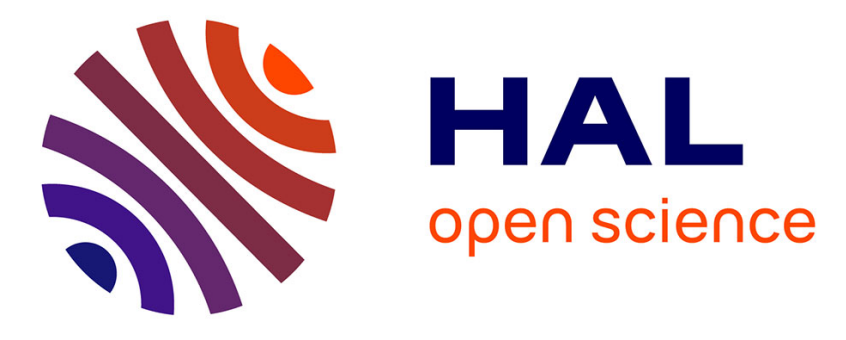

\title{
In-plane littrow lasing of broad photonic crystal waveguides
}

\author{
Omer Khayam, Cyril Cambournac, Henri Benisty, Melanie Ayre, Romain \\ Brenot, Guang Hua Duan, Wolfram Pernice
}

\section{To cite this version:}

Omer Khayam, Cyril Cambournac, Henri Benisty, Melanie Ayre, Romain Brenot, et al.. In-plane littrow lasing of broad photonic crystal waveguides. Applied Physics Letters, 2007, 91 (4), pp.041111. 10.1063/1.2763977. hal-00872830

\section{HAL Id: hal-00872830 \\ https://hal-iogs.archives-ouvertes.fr/hal-00872830}

Submitted on 14 Oct 2013

HAL is a multi-disciplinary open access archive for the deposit and dissemination of scientific research documents, whether they are published or not. The documents may come from teaching and research institutions in France or abroad, or from public or private research centers.
L'archive ouverte pluridisciplinaire HAL, est destinée au dépôt et à la diffusion de documents scientifiques de niveau recherche, publiés ou non, émanant des établissements d'enseignement et de recherche français ou étrangers, des laboratoires publics ou privés. 


\title{
In-plane Littrow lasing of broad photonic crystal waveguides
}

\author{
O. Khayam, ${ }^{\text {a) }}$ C. Cambournac, H. Benisty, and M. Ayre \\ Laboratoire Charles Fabry de l'Institut d'Optique, CNRS, Univ Paris-Sud, Campus Polytechnique, RD 128, \\ F-91127 Palaiseau, France \\ R. Brenot and G.-H. Duan \\ Alcatel-Thales III-V Lab, RD 128, F-91767 Palaiseau, France \\ W. Pernice ${ }^{\text {b) }}$ \\ Department of Engineering Science, University of Oxford, Parks Road, Oxford OX1 3PJ, United Kingdom
}

(Received 18 April 2007; accepted 2 July 2007; published online 26 July 2007)

\begin{abstract}
Broad photonic crystal waveguides forming open resonators are shown to support an hitherto unnoticed lasing pattern. The feedback for lasing originates in Littrow-type reflections of higher-order modes from the waveguide boundaries. The authors employ plane wave and finite-difference time-domain simulations of bulk crystal and waveguide to substantiate the concept of a distributed Littrow reflector. Experimental results are reported for a $10-\mu \mathrm{m}$-wide photonic crystal waveguide deeply etched into InP substrate. In-plane lasing and low modal threshold gain due to longer path lengths are the key features of this resonator. (C) 2007 American Institute of Physics. [DOI: 10.1063/1.2763977]
\end{abstract}

Lasing mechanisms in reported photonic crystal $(\mathrm{PhC})$ lasers can be attributed to two schemes: ${ }^{1}$ (i) photonic bandgap confinement for strong light localization ${ }^{2}$ and (ii) photonic crystal distributed feedback (PCDFB) for gain enhancement of diffraction-coupled Bloch waves., ${ }^{3,4}$ While the former addresses thresholdless lasing in nanosized cavities, the latter enables oscillations in broad-area geometries and open cavities. From an application point of view, the lasing of open resonators is of interest for high-power lasers and semiconductor optical amplifiers (SOAs). Recently, several proposals $^{5,6}$ have demonstrated the PCDFB effect for highpower lasing applications with the advantage of reduced beam filamentation. The waveguide for these devices was a gain strip in a PhC lattice. For the SOA, a welcome feature is an extra lasing oscillation outside the targeted spectral gain window, which clamps the gain and linearizes the output power. Transverse laser clamping was proposed in a verticalcavity surface-emitting laser-type geometry by Genoa Corp. ${ }^{7}$ using one-dimensional distributed Bragg reflectors (DBRs). However, this scheme is demanding in terms of reflectivity and InP-based epitaxy. We show here that a diffraction-based feedback mechanism arises in broad-area two-dimensional (2D) $\mathrm{PhC}$ waveguides for the higher-order modes propagating at non-normal incidence. This mechanism competes favorably against all other modes for in-plane lasing. ${ }^{8}$

Photonic crystals are recognized for their potential as diffraction gratings. ${ }^{9}$ In general, a plane wave incident on a grating structure of period $a$ is diffracted into a set of allowed orders (see inset of Fig. 1). In the classical Littrow configuration an $m$ th order is reflected from the grating back along the incident path, i.e., $\mathbf{k}^{m}=-\mathbf{k}$, where $\mathbf{k}$ is the incident wave vector. This occurs when the component of the incident wave vector parallel to the grating surface $k_{\|}$is exactly $m \pi / a$. In this retro-diffraction, the Littrow order $m$ is defined by its wave-vector components $k_{\|}^{m} \equiv-k_{\|}$and $k_{\perp}^{m} \equiv-k_{\perp}$. For

\footnotetext{
${ }^{\text {a)} E l e c t r o n i c ~ m a i l: ~ o m e r . k h a y a m @ i n s t i t u t o p t i q u e . f r ~}$

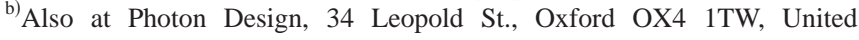
Kingdom.
}

first-order diffraction the set of normalized frequencies $(u=a / \lambda)$ satisfying the Littrow condition is given by $u=1 /(2 n \sin \theta)$, where $n$ is the material index, $\theta$ is the incident angle, and $\lambda$ is the incident wavelength. This relationship is intrinsic to the grating irrespective of its shape and is subsequently called the Littrow curve.

To assess the diffraction efficiency of a Littrow order from a photonic crystal slab, we use Sakoda's method ${ }^{10}$ and produce a "reflectivity map" of the diffraction orders. Figure 1 shows such a map for the first $(m=-1)$ order of diffraction for a TE polarized wave incident on six rows of holes in a matrix of index $n=3.21$, the effective index of our InP-based heterostructure. The PhC lattice is triangular and has an air filling factor of $30 \%$. Superimposed on the map are the Littrow curve (dashed line) and the diffraction cutoff (solid line). It is clear from the map topography that maximal reflectivity occurs for Littrow diffraction. The incident light is hence efficiently diffraction coupled to the first order. The presence of high reflectivity along the lattice symmetry directions $(\Gamma M$ and $\Gamma K)$ is attributed to the distributed feedback mechanisms at the band edges of the $2 \mathrm{D} \mathrm{PhC} \mathrm{lattice.}{ }^{3}$

In a $\mathrm{PhC}$ waveguide geometry, the Littrow condition translates into the Brillouin zone-edge modes at $k_{\|}=\pi / a$

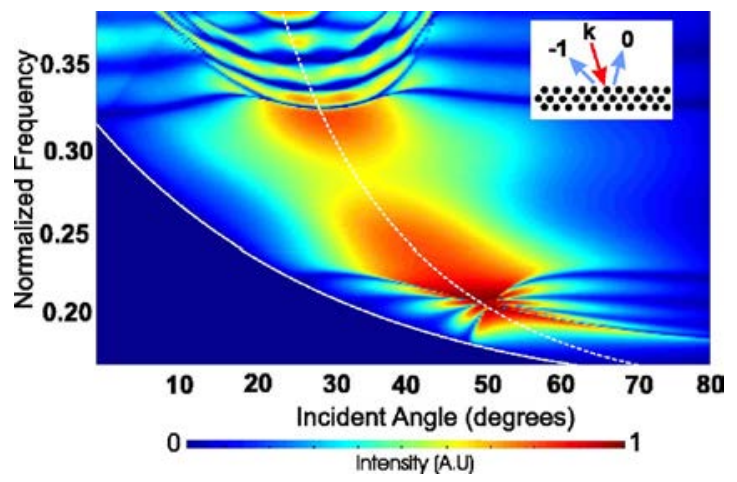

FIG. 1. (Color online) Reflection map of first-order diffraction with Littrow curve (dashed white line) and diffraction cutoff (continuous white line) superimposed. Inset: diffraction geometry. 


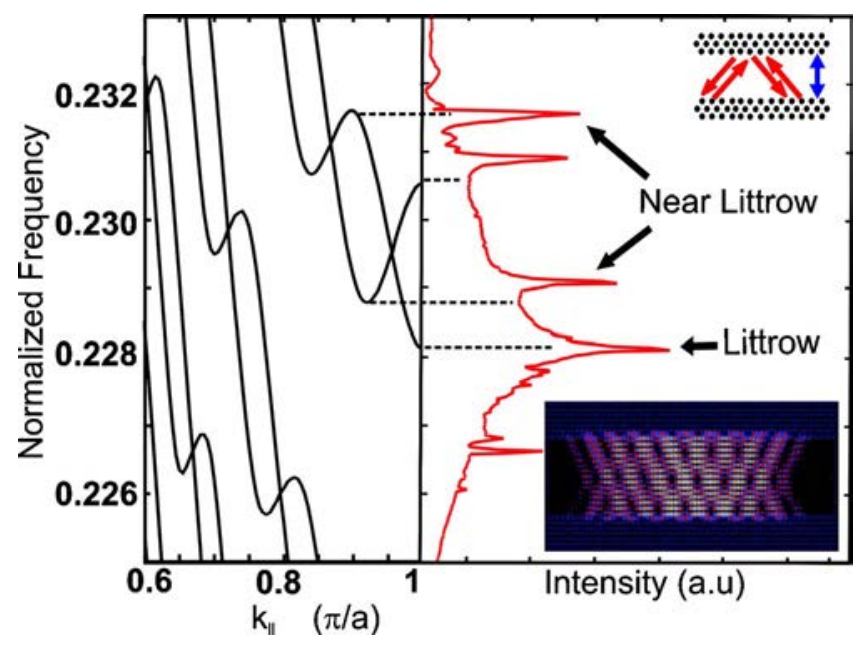

FIG. 2. (Color online) FDTD of W15 active waveguide: lasing spectrum (red) compared to the dispersion diagram. Top inset: photonic crystal waveguide as an open resonator. Oblique arrows show Littrow lasing configuration and vertical arrow shows transverse (FP) lasing. Bottom inset: lasing pattern in the $40-\mu \mathrm{m}$-long $\mathrm{W} 15 \mathrm{PhC}$ waveguide.

which are distinctly different from the Fabry-Perot (FP)-type modes at $k_{\|}=0$. The latter draws its feedback from specular reflections from the waveguide boundary. The two mode types possess different free spectral ranges (FSRs), which becomes an important identification criterion as shall be seen in the experimental spectrum later in this letter. Due to Littrow feedback each higher-order guided mode with its discrete frequency at the zone edge diffracts into itself, and the resulting $\left(\mathbf{k}^{m}, \mathbf{k}\right)$ pair forms a stationary mode (see Fig. 2, top inset) that we shall refer to as the "Littrow mode." Since the feedback between the forward propagating mode and its back-diffracted counterpart is realized over the entire propagation length of the waveguide, the $\mathrm{PhC}$ boundary acts as a distributed Littrow reflector (DLR).

The profile of a Littrow mode is observed from $2 \mathrm{D}$ finite-difference time-domain (FDTD) simulations ${ }^{11,12}$ of a broad $\mathrm{PhC}$ waveguide acting as an open resonator (Fig. 2, bottom inset). We use two $\mathrm{PhC}$ mirrors, each having seven rows of triangular lattice of holes, separated by $15 a \sqrt{3} / 2$ (a so-called $W x$ waveguide, where $x=15$ along $\Gamma K$ ) in a medium with gain centered near one of the Brillouin zone-edge modes. The material gain is assumed to be of Lorentzian line shape (full width at half maximum of $\Delta \lambda=25.5 \mathrm{~nm}$ ) in the proximity of a gain peak at $\lambda=1565 \mathrm{~nm}(u=0.228)$. To simulate gain saturation as a result of carrier depletion, a nonlinear gain model is used where the gain is dependent on the optical intensity. Figure 2 shows the resulting spectrum of the W15 waveguide cavity and its dispersion diagram calculated using the plane-wave method. Good agreement is found between the frequencies of resonant modes and the W15 zone-edge modes, confirming the origin of lasing. We see two categories of lasing peaks: Littrow at $k_{\|}=\pi / a$ and near Littrow at $k_{\|}<\pi / a$. These latter correspond to zero-groupvelocity points located near but not exactly at the Brillouin zone edge. The zigzag lasing is a signature of Littrow feedback (Fig. 2, top inset). Furthermore, the beating between exact and near-Littrow modes manifests itself as the intensity modulation pattern, as seen in Fig. 2 (bottom inset). Note that due to the low threshold gains of Littrow modes, the FP modes are discriminated against and are observed neither in

simulations nor in experiments, as detailed below. also results in local zero-group-velocity points at the anti-
Downloaded 21 Sep 2007 to 129.175.97.14. Redistribution subject to AIP license or copyright, see http://apl.aip.org/apl/copyright.jsp (a)

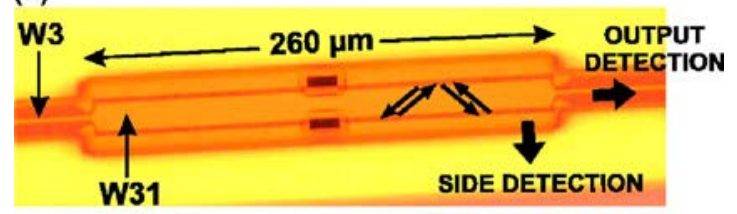

(b)

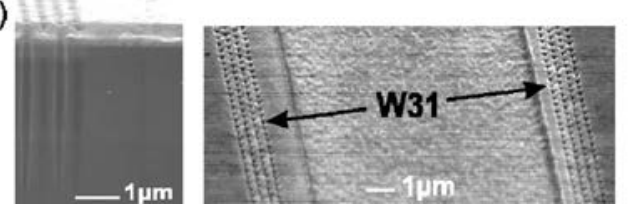

FIG. 3. (Color online) Fabricated structure: (a) top view of the open resonator formed by a broad $2 \mathrm{D} \mathrm{PhC}$ waveguide. The black arrows depict the optical path related to the feedback mechanism. (b) Micrographs of the waveguide showing etched $\mathrm{PhC}$ cladding holes (left) and top view of the waveguide (right).

Our fabricated structure, ${ }^{13}$ designed to experimentally observe Littrow lasing, is essentially a $10-\mu \mathrm{m}$-wide active planar multimode interferometer (MMI) bounded by $\mathrm{PhC}$ mirrors. The mirror separation here equals that of a W31 PhC waveguide. The epitaxial structure of our device is essentially a buried ridge heterostructure grown on a $n$-doped InP substrate $(n=3.17)$. It encapsulates a $118 \mathrm{~nm}$ thick highindex guiding layer made of six InGaAsP quantum wells (gaps at $1.17 \mu \mathrm{m}$ for barriers and at $1.55 \mu \mathrm{m}$ for quantum wells). With 7\% confinement in active wells, $75 \%$ of mode energy is in the cladding. This gives the fundamental transverse mode an effective index of around 3.2. A 2D triangular lattice of holes was defined by e-beam lithography and etched through the heterostructure using inductively coupled plasma-reactive ion etching. The resulting rows of $\mathrm{PhC}$ at either sides of the MMI have a pitch of $400 \mathrm{~nm}$ and a fill factor of $35 \%$. As can be inferred from Fig. 1, at the frequency corresponding to the chosen values of lattice constant and peak gain $(u=a / \lambda=400 / 1550 \approx 0.26)$, the specular order exists for $0^{\circ}<\theta<10^{\circ}$. Thus, above the diffraction cutoff Littrow modes can be discriminated against transverse FP modes. Figure 3 shows the device with W3 access waveguides. For current injection a gold electrode, as seen in Fig. 3(b), is deposited on top of the waveguide core without touching the photonic crystal cladding.

The device is characterized by electrically pumping the waveguide and collecting both the laser emission and the amplified spontaneous emission (ASE) with a lensed fiber connected to an optical spectrum analyzer. As shown in Fig. 3(a), light is collected at two positions: at the waveguide output via W3 and through the sides of the waveguide. Lasing was observed at a threshold current of around $50 \mathrm{~mA}$. Both the side and the output spectra are shown in Fig. 4(a) for an injection current of $200 \mathrm{~mA}$. They exhibit three groups of lasing peaks which we number in order of appearance with the increase in injected current intensity.

To further analyze these results, we note that while the waveguide modes at $k_{\|}=0$ (FP modes) are uncoupled modes with a fixed FSR $\left(\sim \lambda^{2} / 2 n_{g} \mathrm{~W}_{x}\right.$, where $n_{g}$ is the group index $)$, the pattern of modes at the Brillouin zone edge is more complex. As we gradually move away from $k_{\|}=0$ toward the zone edge we enter a parity dependent strong coupling regime that modifies the mode FSR to $\mathrm{FSR}^{\prime}$ at $k_{\|}=\pi / a$. The ratio FSR' /FSR is typically around 0.7 . The mode coupling also results in local zero-group-velocity points at the antiAIP license or copyright, see http://apl.aip.org/apl/copyright.jsp 
(a)
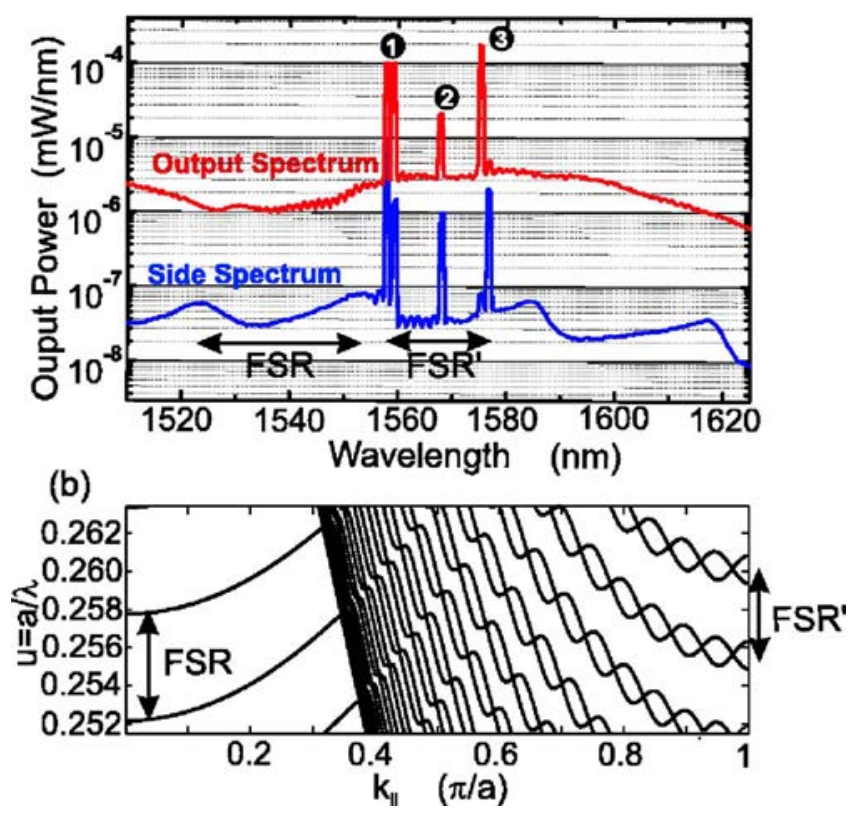

FIG. 4. (Color online) (a) Measured emission spectra of the electrically pumped W31 waveguide. Peaks are labeled in order of appearance. (b) Calculated TE dispersion diagram of a W31 PhC waveguide.

crossings. ${ }^{14}$ Each such point is a potential lasing mode. However, the enhancement of optical density of states at the zone edge privileges a $k_{\|}=\pi / a$ mode (i.e., the Littrow mode) over the near zone-edge mode.

Convincingly, the mode spacing in the lasing spectrum of the W31 $(\sim 18 \mathrm{~nm})$ in Fig. 4(a) is smaller than the FSR and corresponds to that of the Littrow modes, as shown in Fig. 4(b). Side detection of emission helps to collect the purely transverse oscillations across the waveguide, which appear as ASE in the side spectrum (Airy function with angular convolution). ${ }^{15}$ The FSR of the ASE signal $(\sim 30 \mathrm{~nm})$ corresponds to that of the FP modes of waveguide. The presence of this modulation in the emission confirms the fact that the FP modes in the waveguide are in competition with the Littrow modes. However, the latter dominates due to longer effective optical path length and subsequently lower modal threshold gain. ${ }^{16}$

On the basis of agreement between theory and experiment, we have demonstrated a lasing mechanism in broadarea $\mathrm{PhC}$ waveguides that is based on diffraction in Littrow configuration. In analogy with the DBR in one dimension, we call this mechanism the DLR. With the advantage of a planar open cavity configuration, Littrow lasing has a direct application in gain-clamped linear optical amplifiers.

This work was carried out within the framework of European project FUNFOX under Grant No. FP6-IST004582.

${ }^{1}$ H. Benisty and C. Weisbuch, Progress in Optics (Elsevier, Amsterdam, 2006), Vol. 49, pp. 177-289.

${ }^{2}$ O. Painter, R. K. Lee, A. Scherer, A. Yariv, J. D. O’Brien, P. D. Dapkus, and I. Kim, Science 284, 1819 (1999).

${ }^{3}$ M. Notomi, H. Suzuki, and T. Tamamura, Appl. Phys. Lett. 78, 1325 (2001).

${ }^{4}$ E. Miyai, K. Sakai, T. Okano, W. Kunishi, D. Ohnishi, and S. Noda, Nature (London) 441, 946 (2006).

${ }^{5}$ I. Vurgaftman and J. R. Meyer, Appl. Phys. Lett. 78, 1475 (2001).

${ }^{6}$ H. Hofmann, H. Scherer, S. Deubert, M. Kamp, and A. Forchel, IEEE 20th International Semiconductor Laser Conference, Big Island, Hawaii, 2006, Paper No. ThA6.

${ }^{7}$ D. A. Francis, S. P. DiJaili, and J. D. Walker, Proceedings of Optic Fiber Communication Conference, Anaheim, CA, March 2001, post deadline Paper No. 13, pp. 1-3.

${ }^{8}$ O. Khayam, M. Ayre, C. Cambournac, H. Benisty, W. Pernice, and D. Gallagher, Conference on Lasers and Electro-Optics, Baltimore, MD, 2007, Paper No. CWN6.

${ }^{9}$ D. Maystre, Opt. Express 8, 209 (2001).

${ }^{10}$ K. Sakoda, Phys. Rev. B 51, 4672 (1995).

${ }^{11}$ W. H. P. Pernice, D. F. G. Gallagher, and F. P. Payne, 13th European Conference on Integrated Optics, 2007, Paper No. FC6.

${ }^{12}$ CRYSTAlwaVe, Photon Design, UK (http://www.photond.com).

${ }^{13}$ C. Cambournac, O. Khayam, M. Ayre, L. Martinelli, H. Benisty, R. Brenot, F. Pommereau, F. Poingt, E. Derouin, O. Drisse, O. Le Gouezigou, L. Le Gouezigou, and G.-H. Duan, Conference on Lasers and ElectroOptics, Baltimore, MD, 2007, Paper No. CMV5.

${ }^{14}$ S. Olivier, M. Rattier, H. Benisty, C. Weisbuch, C. J. M. Smith, R. M. De La Rue, T. F. Krauss, U. Oesterle, and R. Houdré, Phys. Rev. B 63, 113311 (2001).

${ }^{15}$ Scattering allows their reasonably efficient collection along the sides.

${ }^{16} \mathrm{~A}$ detailed Littrow modal threshold gain analysis is to be published elsewhere. 